\title{
Review of the Recent Progress on GaN-Based Vertical Power Schottky Barrier Diodes (SBDs)
}

\author{
Yue Sun ${ }^{1,2,3}$, Xuanwu Kang ${ }^{2, * \mathbb{D}}$, Yingkui Zheng ${ }^{2}$, Jiang Lu ${ }^{2} \mathbb{D}$, Xiaoli Tian ${ }^{2}$, Ke Wei ${ }^{2}$, \\ Hao Wu ${ }^{2}$, Wenbo Wang ${ }^{1}$, Xinyu Liu ${ }^{2}$ and Guoqi Zhang ${ }^{3, *}$ \\ 1 Beijing Delft Institute of Intelligent Science and Technology, Beijing 101300, China; y.sun-6@tudelft.nl (Y.S.); \\ w.b.wang@bd-iist.com (W.W.) \\ 2 Institute of Microelectronics, Chinese Academy of Sciences, Beijing 100029, China; \\ ZhengYingkui@ime.ac.cn (Y.Z.); LuJiang@ime.ac.cn (J.L.); TianXiaoli@ime.ac.cn (X.T.); \\ WeiKe@ime.ac.cn (K.W.); wuhao@ime.ac.cn (H.W.); xyliu@ime.ac.cn (X.L.) \\ 3 Department of Microelectronics, Delft University of Technology, Delft 2628 CD, The Netherlands \\ * Correspondence: Kangxuanwu@ime.ac.cn (X.K.); G.Q.Zhang@tudelft.nl (G.Z.); \\ Tel.: +86-186-0009-6727 (X.K.)
}

Received: 20 April 2019; Accepted: 22 May 2019; Published: 24 May 2019

\begin{abstract}
Gallium nitride (GaN)-based vertical power Schottky barrier diode (SBD) has demonstrated outstanding features in high-frequency and high-power applications. This paper reviews recent progress on GaN-based vertical power SBDs, including the following sections. First, the benchmark for $\mathrm{GaN}$ vertical SBDs with different substrates ( $\mathrm{Si}$, sapphire, and $\mathrm{GaN}$ ) are presented. Then, the latest progress in the edge terminal techniques are discussed. Finally, a typical fabrication flow of vertical GaN SBDs is also illustrated briefly.
\end{abstract}

Keywords: GaN; Schottky barrier diode (SBD); vertical power devices; edge termination techniques

\section{Introduction}

Today silicon devices have reached their physical limits either in terms of scaling down or in terms of their physical properties [1,2]. To further optimize device performance, new materials must be explored. Wide band gap materials (e.g., silicon carbide ( $\mathrm{SiC}$ ), gallium nitride ( $\mathrm{GaN})$, and diamond) have recently attracted a lot of interest for high power and high temperature applications [3-8]. SiC-based power devices have been already commercialized for high-voltage and high-power application $[9,10]$; diamond is another promising candidate [11,12]. Among all of these wide bandgap semiconductor material, $\mathrm{GaN}$ has a higher electron mobility than $\mathrm{SiC}$ and higher critical electric field than $\mathrm{Si}$ [13]. GaN-based devices are expected to meet the requirements of the future advanced power systems in the field of radio frequency and power conversion application.

The field of power electronics is concerned with the processing of electrical power using electronic devices. Power diodes are essential component in power converters and inverters in power transmission. With the superior physical and chemical properties of $\mathrm{GaN}, \mathrm{GaN}$-based power diodes can significantly increase the efficiency and reduce the energy loss [6,14]. Since the year 2000, GaN-based rectifiers (including Schottky barrier diode (SBD) and PN junction diode) have attracted considerable interest from researchers. With the absence of minority carrier accumulation and low barrier height, SBD can operate at higher frequencies with a lower turn-on voltage $\left(\mathrm{V}_{\mathrm{ON}}\right)$ than the PN junction diode [5]. Yoshimoto et al. [15] demonstrated the operation of GaN SBD at high frequency with low power loss in power converter, comparing them with commercial Si fast recovery diode (FRD) and SiC SBDs via a typical E resonant rectifying tested at a frequency of $30 \mathrm{MHz}$.

The typical schematic structure of GaN SBD is shown in Figure 1a,b, including quasi-vertical and fully-vertical structure [16-22]. For the quasi-vertical GaN SBD, a mesa structure is processed and both 
of the anode and cathode are located at the same side of the wafer, as shown in Figure 1a. Quasi-vertical SBDs have several drawbacks [20,22]: (1) nonuniform distribution of current, (2) the current crowding problems, (3) large total device area, and (4) the deep etched sidewall process. All these issues greatly promote the development of fully-vertical SBD, where the electrodes (anode and cathode) are located at two sides of the wafer separately, with current flowing from anode to cathode through the drift layer in a vertical direction, as shown in Figure 1b. The fully-vertical SBDs have the advantages of effective device size and good thermal performance by cooling from both sides of the wafer.

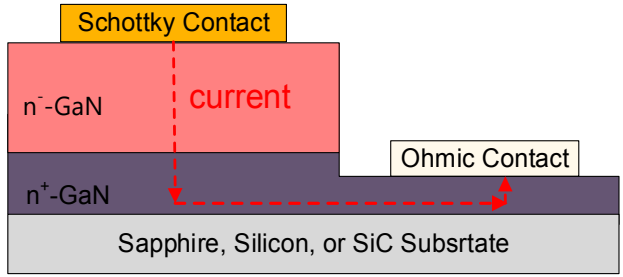

(a)

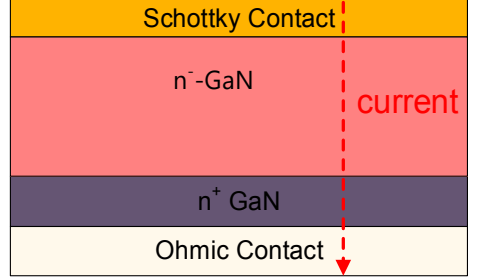

(b)

Figure 1. Gallium nitride Schottky barrier diode (GaN SBD) structure and current flowing directions: (a) quasi-vertical and (b) fully-vertical.

The GaN epitaxy layer grown on GaN substrate has lower dislocation densities than foreign substrates (e.g., $\mathrm{Si}$, sapphire, or $\mathrm{SiC}$ ), because of low lattice mismatch and low thermal expansion coefficient mismatch [20-27]. However, the dislocation density of GaN-on-GaN is limited by the defect density in the GaN substrate [28-30]. Before 2010, most GaN SBD devices were fabricated on a foreign substrate, as a result of the poor availability of bulk GaN (or free-standing) substrates. Most studies of vertical GaN-on-GaN SBD power devices have appeared in the last decade [31,32]. Moreover, with the appearance of the quasi-vertical device and novel device structures [33,34], sapphire and Si substrates have been investigated in recent years [35-38].

The main objective in the design of power devices is to obtain a high breakdown voltage (BV) while keeping the $\mathrm{R}_{\mathrm{ON} \text {,sp }}$ as low as possible [39]. However, a large number of dislocations in the GaN drift layer can cause leakage current when device is reverse biased $[40,41]$. To study the substrates impact on the performance of GaN-based power device, Figure 2 summarizes the data from literatures of GaN vertical SBDs with different substrates. The $\mathrm{R}_{\mathrm{ON}, \text { sp }}$ versus BV characteristics of $\mathrm{GaN}$ vertical SBD devices is still far from the ideal GaN limit [30]. The GaN homoepitaxial has low dislocations and high crystal quality, thus SBD shows much better performance than heteroepitaxial SBD.

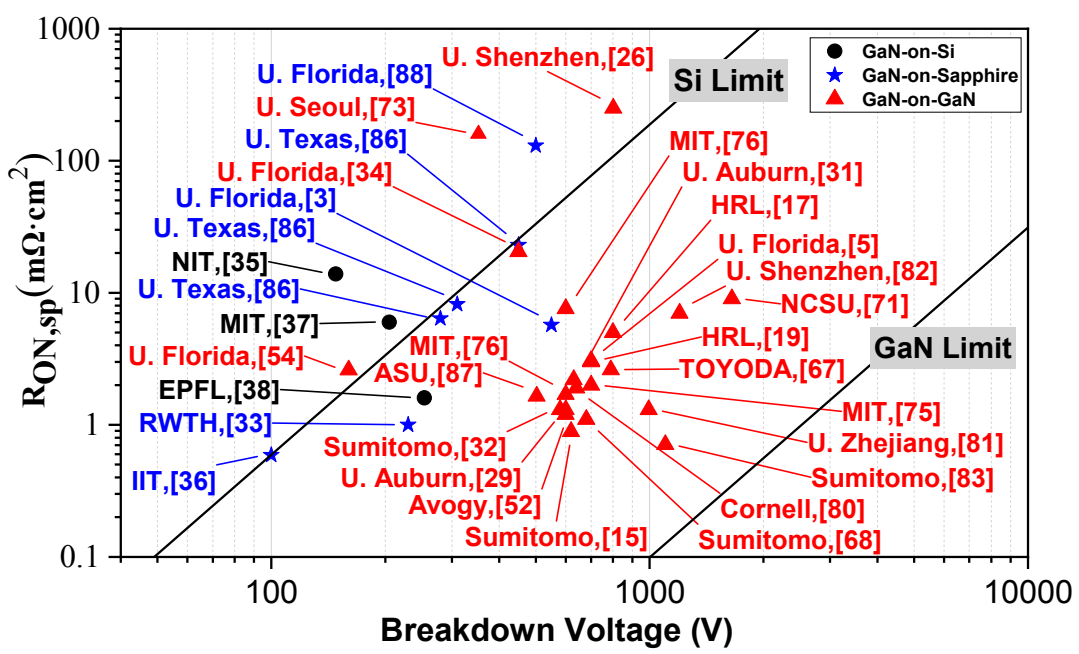

Figure 2. Benchmarks of the $\mathrm{R}_{\mathrm{ON}, \mathrm{sp}}$ vs. breakdown voltage (BV) of vertical SBDs with $\mathrm{GaN}$ on $\mathrm{Si}$, sapphire, and GaN substrates. 
This paper reviews the recent progress of vertical GaN SBD from literatures. The following aspects are covered; the device characteristics of GaN-based SBD in Section 2, terminal edge techniques in Section 3, the typical fabrication flow of vertical GaN SBD in Section 4, and the conclusion in Section 5.

\section{Device Characteristics of Vertical GaN SBDs}

This section focuses on the forward and reverse characteristics of vertical SBD. A typical SBD structure and its electric field distribution under reverse bias are shown in Figure $3 a, b$. It reveals that the maximum electric field is located at the interface between anode and semiconductor $[42,43]$.

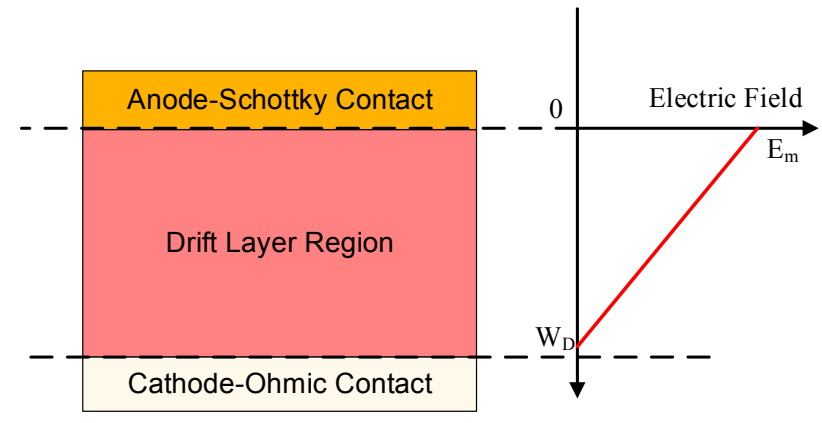

(a)

(b)

Figure 3. (a) Basic SBD structure and (b) electric field distribution.

\subsection{Forward Conduction Characteristics}

A conventional SBD structure consists of anode metal, drift layer, substrate, and cathode metal. When the diode is working in on-state, the turn-on voltage $\left(\mathrm{V}_{\mathrm{ON}}\right)$, and $\mathrm{R}_{\mathrm{ON}}$ are the important parameters [44]. For a vertical power Schottky diode, from the theory of the thermionic emission, the $\mathrm{V}_{\mathrm{ON}}$ of an SBD can be expressed as [45]

$$
V_{O N}=\frac{n k T}{q} \ln \left(\frac{J_{O N}}{A^{* *} T^{2}}\right)+n \varnothing_{B}+R_{O N} J_{F}
$$

where $J_{\text {on }}$ is the forward current at $V_{\mathrm{ON}}, n$ is the ideality factor of the Schottky contact, $A^{* *}$ is the effective Richardson's constant, $\Phi_{\mathrm{B}}$ is the Schottky barrier height $(\mathrm{SBH})$, and $R_{\mathrm{ON}}$ is the on-resistance. The ambipolar diffusion coefficient Richardson's constant is expressed as

$$
A^{* *}=\frac{4 \pi q m_{n}^{*} k^{2}}{h^{3}}
$$

where $m_{\mathrm{n}}{ }^{*}$ is the effective electron quality and $h$ is Planck's constant. The theoretically calculated value of $A^{* *}$ for $\mathrm{GaN}$ is $26.4 \mathrm{~A} \cdot \mathrm{cm}^{-2} \cdot \mathrm{K}^{-2}$. Combining Equations (1) and (2), $\mathrm{V}_{\mathrm{ON}}$ is determined mainly by the Schottky barrier height and on-state resistance.

The total specific series resistance $\left(\mathrm{R}_{\mathrm{S}, \mathrm{sp}}\right)$ consists of three parts: the ohmic contact resistance of the cathode $\left(\mathrm{R}_{\text {Cont }}\right)$, the substrate resistance $\left(\mathrm{R}_{S u b}\right)$, and the specific on-state resistance of the drift layer $\left(R_{D, s p}\right)$. The ideal $\mathrm{R}_{\mathrm{ON}, \mathrm{sp}}$ is equal to $\mathrm{R}_{\mathrm{D}, \mathrm{sp}}$ in vertical SBD devices and given by [46]

$$
\begin{gathered}
R_{S, s p}=R_{D, s p}+R_{S u b}+R_{C o n t} \\
R_{D, s p}=\frac{W_{D}}{q \mu_{n} N_{D}}
\end{gathered}
$$

where $W_{D}$ is thickness of the depletion region, $q$ is the electronic charge, $\mu_{n}$ is the electron mobility, and $N_{D}$ is the doping concentration of the drift layer. The depletion width $W_{D}$ under a certain $B V$ is given by 


$$
W_{D}=\frac{2 B V}{E_{C}}
$$

The $N_{D}$ can be expressed as

$$
N_{D}=\frac{\varepsilon_{s} E_{c}^{2}}{2 q B V}
$$

where $E_{\mathrm{c}}$ is the critical electric field of the material and $\varepsilon_{\mathrm{s}}$ is the dielectric constant of the drift layer.

The specific capacitance (capacitance per unit area) associated with this depletion region is given by

$$
C_{S B D, s p}=\frac{\varepsilon_{S}}{W_{D}}
$$

\subsection{Reverse Breakdown Characteristics}

From Equations (5) and (6), the relationship of $W_{D}, N_{D}$ and $B V$ can be expressed as

$$
\mathrm{BV}=E_{c} W_{D}-\frac{q N_{D} W_{D}^{2}}{2 \varepsilon}
$$

According to the Equation (8), the reverse breakdown voltage is inversely dependent on the doping level in the drift layer and positively dependent on the depletion width. For example, in the quasi-vertical SBDs, increasing the depth of the mesa region, further leading to increase of the effective thickness in the drift layer, can help improve the BV characteristics. Low $N_{D}$ or high $W_{D}$ of the drift layer results in a high $\mathrm{BV}$, however, with an increase of $R_{O N}$ characteristics.

According to Equations (3)-(6), the relationship between $R_{\mathrm{ON}, \mathrm{sp}}$ and $\mathrm{BV}$ can be expressed as [14]

$$
R_{O N, s p}=\frac{4 B V^{2}}{\varepsilon_{s} \mu_{n} E_{C}^{3}}
$$

where $\varepsilon_{s} \mu_{n} E_{c}$ is the intrinsic properties of semiconductor materials, commonly referred to as Baliga's figure

\begin{tabular}{|c|c|c|c|c|c|c|c|}
\hline Materials & $E_{g}(e V)$ & $\varepsilon$ & $\begin{array}{c}\mu_{\mathrm{n}} \\
\left(\mathrm{cm}^{2} / \mathrm{V} \cdot \mathrm{s}\right)\end{array}$ & $\begin{array}{c}E_{c} \\
(\mathrm{MV} / \mathrm{cm})\end{array}$ & $\begin{array}{c}V_{\text {sat }} \\
\left(10^{7} \mathrm{~cm} / \mathrm{s}\right)\end{array}$ & $\begin{array}{c}\text { Total Dislocation } \\
\left(\mathrm{cm}^{2}\right)\end{array}$ & $\begin{array}{c}\text { Thermal Conductivity } \\
(\mathrm{W} / \mathrm{m} \cdot \mathrm{K})\end{array}$ \\
\hline $\mathrm{Si}$ & 1.12 & 11.8 & 1350 & 0.3 & 1 & - & 145 \\
\hline GaAs & 1.42 & 13.1 & 8500 & 0.4 & 2 & - & 50 \\
\hline $4 \mathrm{H}-\mathrm{SiC}$ & 3.26 & 10 & 720 & 2.0 & 2 & $>10^{2}$ & 370 \\
\hline $\mathrm{GaN}$ & 3.44 & 9 & 1250 & 3.3 & 2.5 & $>10^{5}$ & 253 \\
\hline Diamond & 5.5 & 5.7 & 2000 & 13.0 & 1.5 & $>10^{4}$ & 2290 \\
\hline
\end{tabular}
of merit (BFOM). Table 1 lists the physical properties of $\mathrm{Si}, \mathrm{GaAs}, \mathrm{SiC}, \mathrm{GaN}$, and Diamond $[8,42,47,48]$. The critical electric field of $\mathrm{GaN}$ is 11 times greater than $\mathrm{Si}$ and the saturation velocity is 2.5 times greater than Si.

Table 1. Physical properties of $\mathrm{Si}, \mathrm{GaAs}, \mathrm{SiC}, \mathrm{GaN}$, and diamond.

$\mathrm{E}_{\mathrm{g}}$, energy bandgap; $\varepsilon$, relative dielectric constant; $\mu_{\mathrm{n}}$, electron mobility; $\mathrm{E}_{\mathrm{c}}$, critical electric field; $\mathrm{V}_{\text {sat }}$, saturation velocity

According to the equations above, the ideal $\mathrm{R}_{\mathrm{ON}, \mathrm{sp}}$ for the drift region of a vertical power device is given by $[14,30]$

$$
\begin{gathered}
R_{o n, s p}(\mathrm{Si})=5.93 \times 10^{-9} B V^{2.5} \\
R_{o n, s p}(4 \mathrm{H}-\mathrm{SiC})=2.97 \times 10^{-12} B V^{2.5} \\
R_{o n, s p}(\mathrm{GaN})=3.12 \times 10^{-12} B V^{2.5}
\end{gathered}
$$

A large number of traps and threading dislocations exist in $\mathrm{GaN}$ materials in reality. The presence of unintentional surface defect donors (e.g., nitrogen vacancy) can cause a reduction of the effective 
width of Schottky barrier, resulting in high leakage current under reverse bias, explained by the thin surface barrier (TSB) model [49]. Trap-assisted tunneling (TAT) is another trap-related leakage conduction mechanism [50]. Besides of the leakage induced by traps, threading dislocation is also a main cause of the devices leakage when device is reverse biased.

Temperature has a strong impact on leakage current under high reverse bias. The thermionic emission is positive correlated with temperature, thus, the Frenkel-Poole Emission (PFE) is a domination conduction mechanism in vertical GaN Schottky diodes at high electronic field and high temperature [11,51]. Additionally, trap-assisted tunneling (TAT) is also a temperature-dependent mechanism that causes increase in leakage current [50].

In a vertical power device, the peak electric field is crowded at the interface between the Schottky contact metal and the n-GaN drift layer, as shown in Figure 4, causing early device breakdown at the edge under reverse bias. Thus, novel terminal techniques are need to improve the vertical device breakdown.

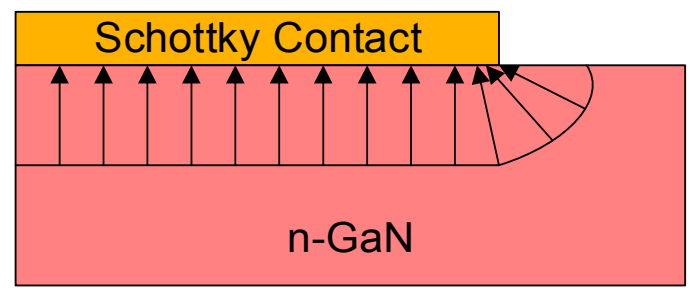

Figure 4. Electric field distribution of a typical vertical SBD under reverse bias.

\section{Edge Termination Techniques}

Edge termination techniques are proposed and utilized to improve the crowded electric field at the periphery of active region. The most commonly used termination techniques are discussed in this section, including field rings, junction termination extension (JTE), field plates, trench termination, reduced surface field (RESURF), and N-based termination.

\subsection{Field Rings}

A planar junction termination structure adopting the $\mathrm{p}-\mathrm{GaN}$ region can provide the redistribution of high electric field at the edge of Schottky contact metal [30], as shown in Figure 5a. The p-GaN termination regions are formed by $\mathrm{Mg}+$ ion implantation under anode edges in the $\mathrm{n}-\mathrm{GaN}$ drift layer.

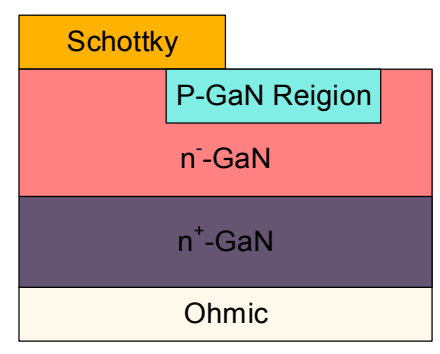

(a)

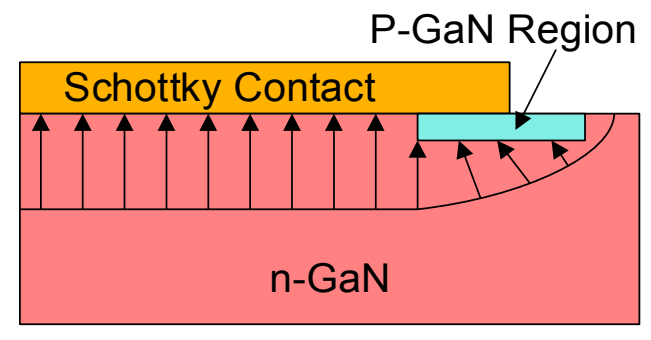

(b)

Figure 5. (a) Cross-section of GaN SBDs with p-guard ring edge termination structure and (b) E-field distribution under reverse bias.

In early 2002, a research group from the University of Florida [50,51] reported a vertical GaN-on-GaN SBD structure with p-guard ring junction termination. They found that a GaN SBD with p-guard ring termination structure has a BV of $160 \mathrm{~V}$. As shown in Figure $5 \mathrm{~b}$, the superior characteristics are obtained by "moving" the peak electric field at edge away from the surface into bulk with the help of depletion region in PN junction. Furthermore, the peak electric field at the edges can be reduced by extension of PN junction in depletion layer. However, the $\mathrm{p}^{+}-\mathrm{GaN}$ implantation method with 
high-temperature annealing conditions can increase the significant risk and complexity of the p-guard ring fabrication [52-58].

Comparing with the n-type GaN dopant process (Si implantation, activation temperature of $1250{ }^{\circ} \mathrm{C}$ [59]), p-GaN dopants require a higher annealing temperature of $1340^{\circ} \mathrm{C}$ to activate $\mathrm{Mg}$ ions [60]. A low activation ration of $\mathrm{Mg}^{+}$for $\mathrm{GaN}$ results in low hole concentration, which can affect the GaN crystal quality causing low mobility and carrier concentration. The poor activation of dopants $\left(\mathrm{Mg}^{+}\right.$ atoms) has only produced $10^{15}-10^{17} \mathrm{~cm}^{-3}$ orders of magnitude of the carrier concentration [21]. Besides, the extremely high temperatures required to activate the implanted $\mathrm{Mg}$ during the annealing process also damage the GaN surface [61,62]. Greenlee, J.D., et al. [63] reported that the second annealing process followed by multicycle rapid thermal annealing (MRTA) process can compensate for the defects of the GaN surface and improve the crystalline quality of implanted p-GaN.

\subsection{Junction Termination Extension (JTE)}

The $\mathrm{p}$-type region formed by $\mathrm{Mg}+$ implantation can redistribute the surface electric field at the edge of the PN junction. This p-type region has been named JTE [64]. Koehler et al. [61] reported a GaN junction barrier-controlled Schottky (JBS) device with a JTE structure in 2016. Their study shows an improved reverse characteristic in JBS with JTE, achieving a higher BV of $610 \mathrm{~V}$ than conventional SBD (BV of $200 \mathrm{~V})$. In the JBS rectifier, the forward current is designed to flow in the undepleted gaps between the $\mathrm{P}^{+}$regions when the diode is forward biased to keep in unipolar operation mode [65]. The pn junction below Schottky metal creates a potential barrier to shield the Schottky contact under reverse bias $[13,30]$.

\subsection{Field Plates}

The field plate is another technique to redistribute the electric field at the edge of the Schottky contact metal under reverse bias. Currently, three types of field plates are used for SBDs, including a metal field plate (Figure 6a), a resistive field plate (Figure 6b), and a floating field plate (Figure 6c). As shown in Figure 6d, the field plate located at the edge of an electrode can extend the depletion boundary and reduce electric field crowding under the reverse bias [66].

The metal field plate is formed by extending the contact metal over the field oxide/dielectrics at the edge of the junction [67], as shown in Figure 6a. In 2009, Horii et al. [68] demonstrated improved reverse characteristics in vertical GaN SBDs with a metal field plate (FP) for the first time, achieving $680 \mathrm{~V}$ of BV (400 V of BV without FP). Zhang et al. [37,69] was the first to report a quasi-vertical GaN-on-Si SBD where the destructive BV of the SBD without and with a FP structure is $90 \mathrm{~V}$ and $205 \mathrm{~V}$, respectively.

Resistive field plate is an alternative field plate technique to smooth the electric field around the surface. This high-resistivity region can help spread the electric field at the edge of the anode metal. As shown in Figure 6b, Ozbek and Baliga [70,71] reported two types of GaN SBDs with a resistive field plate formed by Ar ion implantation on $\mathrm{GaN}$ and sapphire substrates, respectively. The vertical GaN-on-GaN SBD shows a higher breakdown voltage of $1650 \mathrm{~V}$ compared with the diodes without termination (BV of $300 \mathrm{~V}$ ) [70]. Another GaN-on-Sapphire SBD show a BV of $1700 \mathrm{~V}$ with a resistive field plate, which is four times higher than that of the conventional SBD [71].

The structure of GaN SBD with floating field plate is shown in Figure 6c. When a negative bias is applied to the floating metal plate (or biased field plate) on a n-GaN drift layer it repels electrons away from the device surfaces. This will result in an expansion of the depletion region and then the peak electric field can be reduced around the edges. Thus, vertical SBDs with a biased field plate termination can achieve higher BV than devices without it. However, the introduction of an additional package terminal to provide a separate bias to the biased field plate increases the additional bias circuit cost [72]. Seung-Chul et al. [73] demonstrated that vertical GaN SBDs with a metal floating field plate termination has a higher BV of $353 \mathrm{~V}$ than conventional structure $(159 \mathrm{~V})$. 


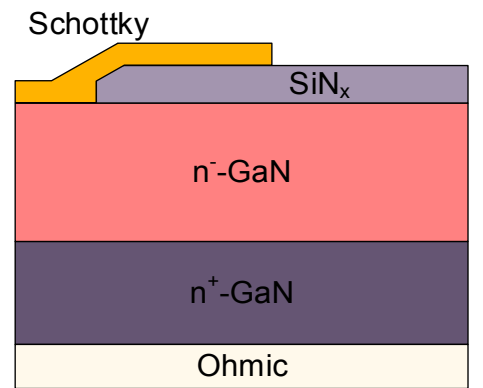

(a)

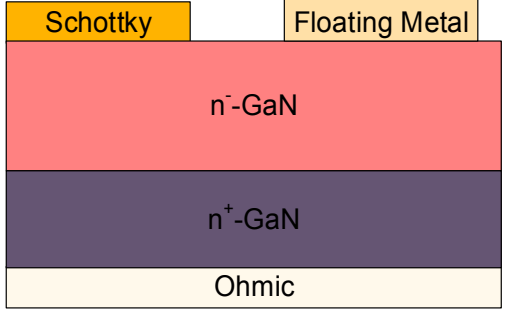

(c)

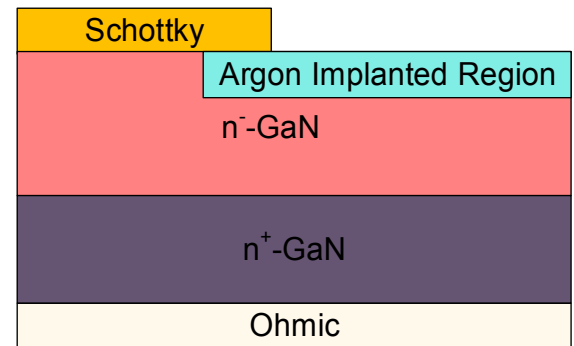

(b)

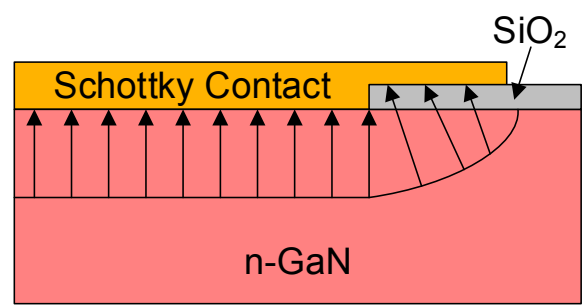

(d)

Figure 6. Schematic cross-section of a field plate with GaN SBDs: (a) metal field plate, (b) resistive field plate, (c) floating field plate, and (d) E-field distribution under reverse bias.

\subsection{Trench Termiantion}

Baliga [66] investigated a typical trench metal oxide semiconductor (MOS) barrier Schottky (TMBS) rectifier structure consisting of an MOS structure at the trench region, as shown in Figure 7a. A trench region containing an MOS structure produces a potential barrier that can shield the Schottky contact at the reverse bias. The potential barrier is against the high electric field in the bulk of the GaN drift region. The reduction of the electric field around Schottky metal enables the reduction of the leakage current under reverse bias [74]. However, it has oxide layer reliability issues due to the high electric field at the corner of the trench.

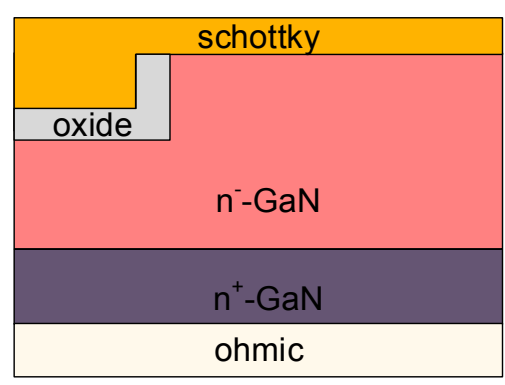

(a)

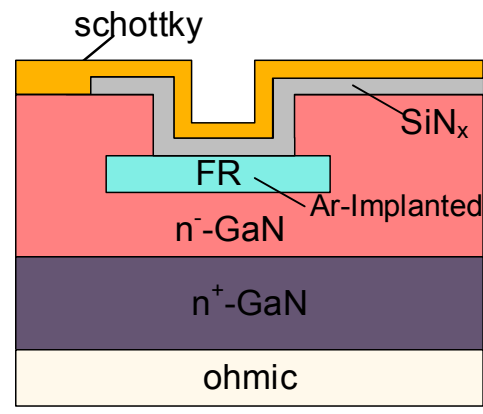

(b)

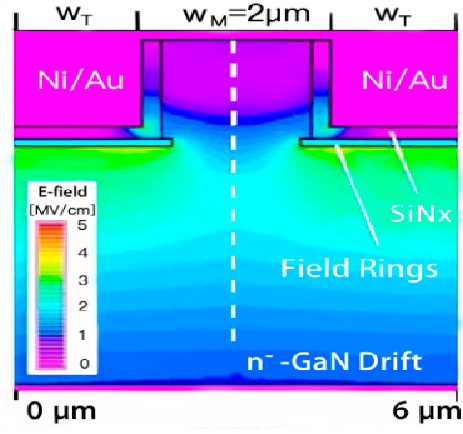

(c)

Figure 7. Schematic cross-section of vertical GaN TMBS: (a) typical structure, (b) FR-TMBS structure, and (c) simulated E-field distribution of FR-TMBS at -1000 V.

Zhang et al. [75] reported a novel GaN trench metal-insulator-semiconductor (MIS) barrier Schottky diode with trench field rings, as shown in Figure 7b. They demonstrated that the GaN vertical FR-TMBS has a higher BV (700 V) than conventional SBDs (400 V). The FR regions were formed by Ar ion implantation, which could avoid a peak electric field at the trench corner and premature breakdown in the oxide layer. The electric field distribution at $-1000 \mathrm{~V}$ along the vertical cutline in the trench is shown in Figure 7c. Zhang et al. [76] also reported a vertical GaN-JBS with Ar-implanted trench termination, achieving a BV of $500-600 \mathrm{~V}$. 


\subsection{Reduced Surface Field (RESURF)}

Planar junction termination is an effective technique to improve breakdown voltage. RESURF is the most popular termination techniques in the design of high-voltage power devices. RESURF vertical SBDs can achieve a high BV since the depletion of the Schottky contact in the vertical direction is reinforced by the adjacent PN junction [77-79]. Li et al. [80] studied the reduced surface field (RESURF) impact on JBS diodes, and reported that the vertical surface field within the trench is much reduced compared to conventional SBD, as shown in Figure 8b.

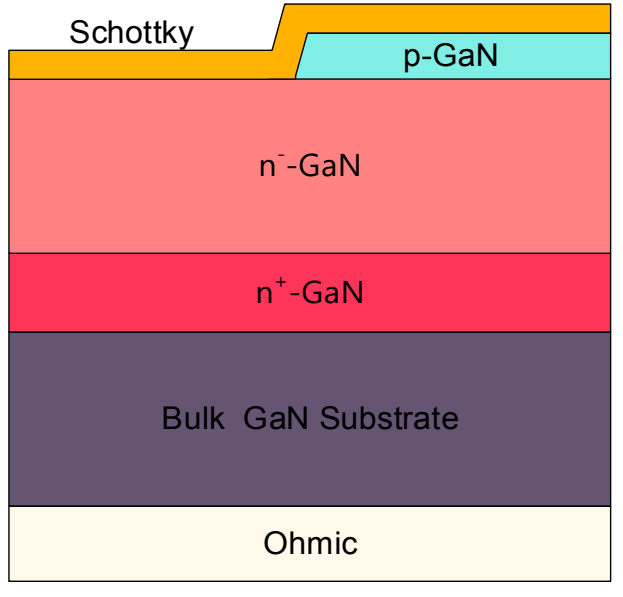

(a)

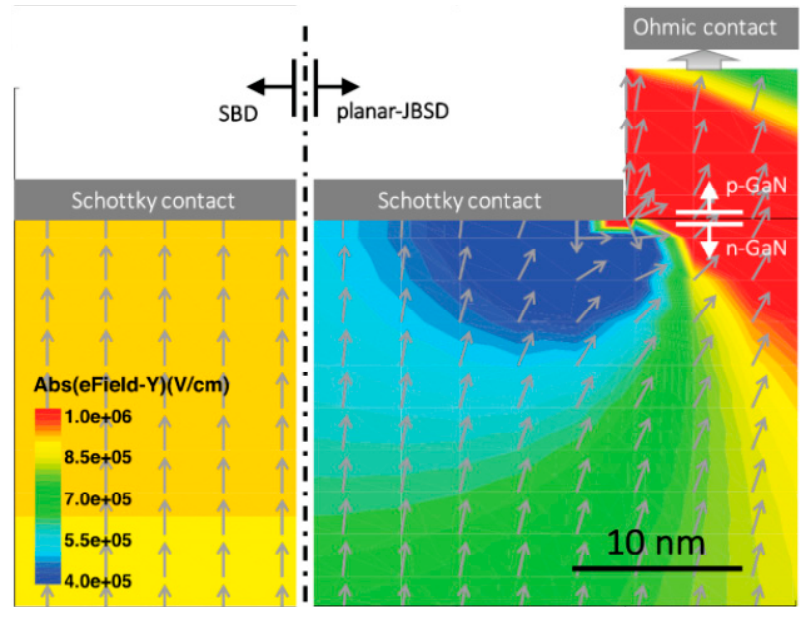

(b)

Figure 8. (a) Schematic cross-sections of GaN reduced surface field (RESURF) junction barrier-controlled Schottky (JBS) structure and (b) comparison of simulated E-field distribution of typical SBD with RESURF JBS at $-200 \mathrm{~V}$.

\subsection{N-Based Termination}

$\mathrm{N}$-based termination (NT) techniques was reported by Yang et al. [6,81], as shown in Figure 9. By utilizing the nitridation plasma to form an N-based termination region around the edge of the anode, the $\mathrm{N}$ vacancies can be compensated and the Ga dangling bonds on the $\mathrm{GaN}$ surface can also be passivated. The NT structure at the junction edge presents a higher energy barrier height and/or effective barrier thickness around vertical GaN SBDs. Therefore, the leakage current at the edge is decreased under reverse bias due to the suppression of electron transport via thermionic-field emission (TFE) or tunneling. The NT-SBD with a BV of $995 \mathrm{~V}$ and a $\mathrm{R}_{\mathrm{ON}, \mathrm{sp}}$ of $1.2 \mathrm{~m} \Omega \cdot \mathrm{cm}^{2}$ has shown excellent static (high $\mathrm{J}_{\mathrm{F}}$ density of $2000 \mathrm{~A} / \mathrm{cm}^{2}$ ) and switching characteristics (fast reverse recovery time of $\sim 17 \mathrm{~ns}$ and small reverse recovery charge of $\sim 0.8 \mathrm{nC}$ ), which impart potential advantages in high-power and high-frequency applications.

In summary, the benchmark for different edge termination techniques is shown in Figure 10. A resistive FP termination device with low donor concentration $\left(N_{D}=1 \times 10^{14} \mathrm{~cm}^{-3}\right)$ has the highest BV $(1.6 \mathrm{kV})$ in this map [71], a TiN-based GaN SBD is followed $(1.2 \mathrm{kV})$ without any termination technique [82]. Utilizing a metal FP termination with low drift layer donor concentration $\left(\mathrm{N}_{\mathrm{D}}=8 \times 10^{15} \mathrm{~cm}^{-3}\right)$ can significantly increase the BV $(1.1 \mathrm{kV})$ [83]. Trench termination technique might not evidently improve the BFOM of SBDs, comparing with other techniques, explained by high donor concentration $\left(\mathrm{N}_{\mathrm{D}}=2 \times 10^{16} \mathrm{~cm}^{-3}\right)$ in the GaN drift layer [39]. N-based termination structure has a similar reverse breakdown characteristic (BV of $995 \mathrm{~V}$ ) with metal FP (BV of $1.1 \mathrm{KV}$ ) except for high $\mathrm{R}_{\mathrm{ON}}$, attributed to a relative thick drift layer $(11 \mu \mathrm{m})[6]$. 


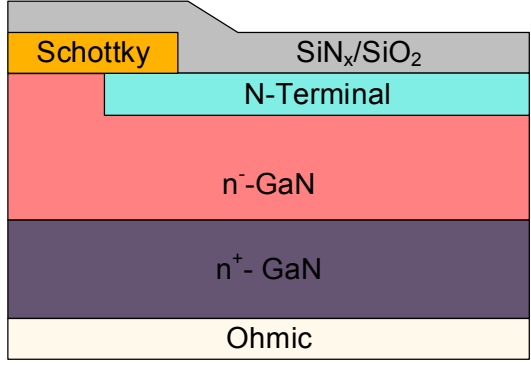

(a)

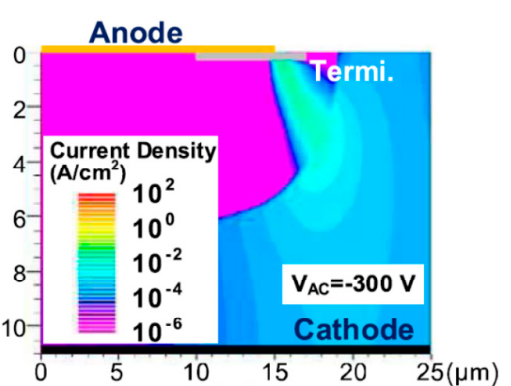

(b)

Figure 9. (a) Schematic cross-section of the vertical GaN NT-SBD and (b) simulated leakage current distribution of NT-SBD at $-300 \mathrm{~V}$.

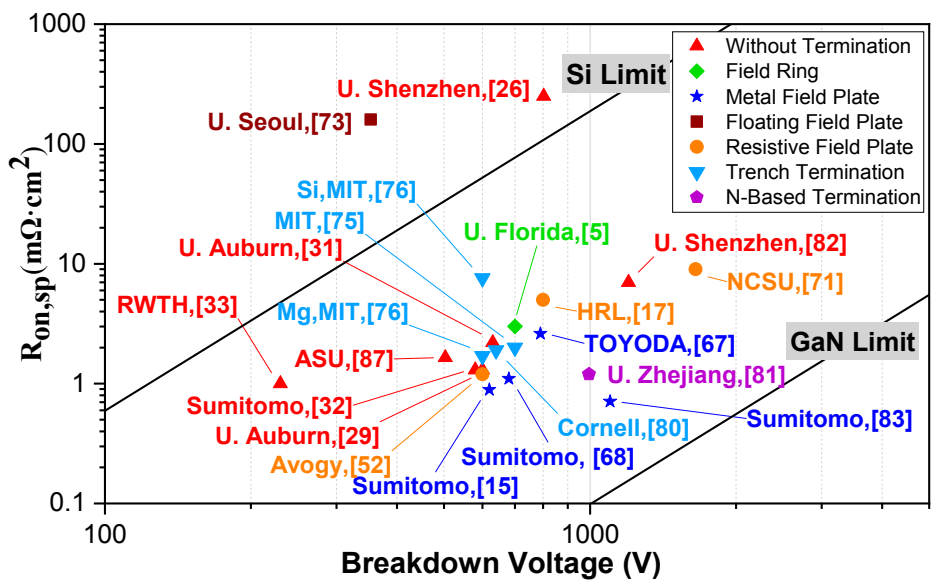

Figure 10. Benchmarks of the $\mathrm{R}_{\mathrm{ON}, \mathrm{sp}}$ vs. BV of vertical SBDs with different edge termination techniques.

\section{Fabrication Steps of Vertical GaN SBDs}

A proposed process flow of vertical GaN SBD has been shown in Figure 11, which is similar to the literature [84]. The GaN epilayer was subsequently grown on sapphire substrates by metal organic chemical vapor deposition (MOCVD) [85]. In Figure 11a, the contact metal was deposited on $\mathrm{GaN}$ epilayer. After that, the samples were annealed at a certain condition to further improve the ohmic behavior. (Ti/Al/Ni/Au at $600-840{ }^{\circ} \mathrm{C}$ in $\mathrm{N}_{2}$ for $20-30$ s $[2,26,29,33,65,67,71,72]$; Ti/Al/Pt/Au at $700{ }^{\circ} \mathrm{C}-850{ }^{\circ} \mathrm{C}$ in $\mathrm{N}_{2}$ for 30 s $[5,53,54,86]$; Ti/Al [19,31,37,38,68,75,76,82]; Ti/Al/Ti/Au [32,67,83,87]; $\mathrm{Ti} / \mathrm{Al} / \mathrm{Au}[18,81]$.) Then, the nickel layer is formed on ohmic contact metal by an electroplating process, as shown in Figure 11b. To remove the sapphire substrate, a laser power was used to cause local heating at the $\mathrm{GaN} /$ sapphire interface which in turn lead to the decomposition of the GaN, as shown in Figure $11 \mathrm{c}$,d. Finally, the Schottky metal (Ni/Au) was deposited using e-beam evaporation, as shown in Figure 11e.

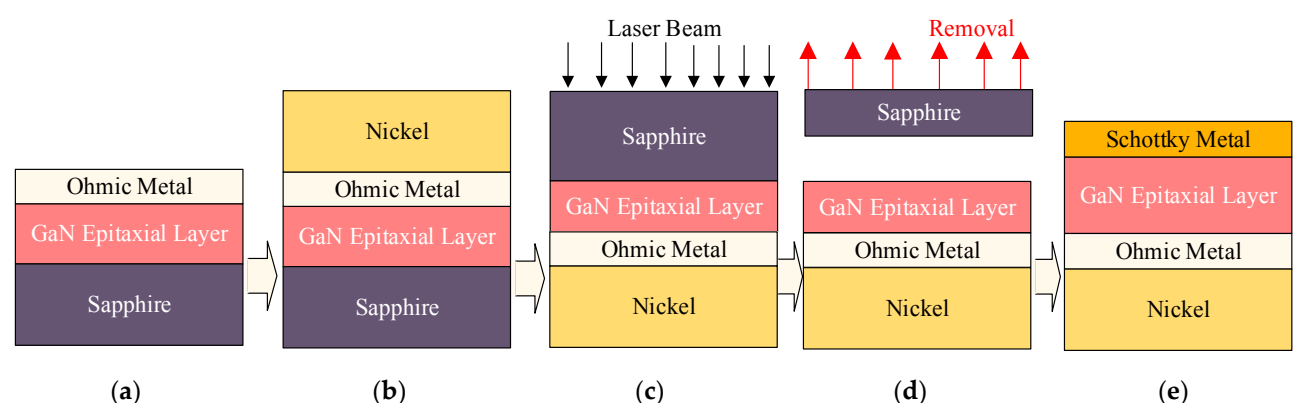

Figure 11. Vertical GaN SBD device process flowchart: (a) ohmic contact, (b) nickel electroplating, (c) laser lift-off, (d) sapphire removal, and (e) Schottky contact. 


\section{Conclusions}

This paper reviewed and summarized the reported GaN vertical power SBDs (Table 2). The recent progress of $\mathrm{GaN}$ vertical power $\mathrm{SBD}$ on different substrates has been presented. The $\mathrm{R}_{\mathrm{ON} \text {,sp }}$ versus $\mathrm{BV}$ characteristics of GaN vertical SBD devices is still far from the ideal GaN limit [30]. The GaN homoepitaxial has low dislocations and high crystal quality, thus SBD shows much better performance than GaN heteroepitaxial SBD.

Table 2. Summary of the reported vertical GaN power SBDs in the literature.

\begin{tabular}{|c|c|c|c|c|c|c|c|c|}
\hline Year & Substrate & $\begin{array}{l}\text { BV } \\
\text { (V) }\end{array}$ & $\begin{array}{c}\mathrm{R}_{\mathrm{ON}, \mathrm{sp}} \\
\left(\mathrm{m} \Omega \cdot \mathrm{cm}^{2}\right)\end{array}$ & $\begin{array}{c}\mathrm{V}_{\mathrm{ON}} \\
(\mathrm{V})\end{array}$ & $\begin{array}{l}\text { Schottky } \\
\text { Metal }\end{array}$ & $\begin{array}{l}\text { Ohmic } \\
\text { Metal }\end{array}$ & Manufacturer & Ref. \\
\hline 1999 & Sapphire & 450 & NA & 4.2 & $\mathrm{Au}$ & $\mathrm{Ti} / \mathrm{Al} / \mathrm{Ni} / \mathrm{Au}$ & CIT & [7] \\
\hline 2000 & Sapphire & 550 & 5.7 & 3.5 & NA & $\mathrm{Pt} / \mathrm{Au}$ & U. Florida & [3] \\
\hline 2000 & Sapphire & 450 & 23 & N.A & $\mathrm{Pt} / \mathrm{Au}$ & $\mathrm{Ti} / \mathrm{Al} / \mathrm{Pt} / \mathrm{Au}$ & U. Texas & [86] \\
\hline 2000 & Sapphire & 310 & 8.2 & N.A & $\mathrm{Pt} / \mathrm{Au}$ & $\mathrm{Ti} / \mathrm{Al} / \mathrm{Pt} / \mathrm{Au}$ & U. Texas & [86] \\
\hline 2000 & Sapphire & 280 & 6.4 & N.A & $\mathrm{Pt} / \mathrm{Au}$ & $\mathrm{Ti} / \mathrm{Al} / \mathrm{Pt} / \mathrm{Au}$ & U. Texas & [86] \\
\hline 2000 & Sapphire & 500 & 130 & 3.5 & $\mathrm{Ni} / \mathrm{Pt} / \mathrm{Au}$ & $\mathrm{Ti} / \mathrm{Al} / \mathrm{Pt} / \mathrm{Au}$ & U. Florida & [88] \\
\hline 2001 & $\mathrm{GaN}$ & 450 & 20.5 & 3 & $\mathrm{Pt} / \mathrm{Au}$ & $\mathrm{Ti} / \mathrm{Al}$ & U. Florida & [34] \\
\hline 2001 & GaN & 700 & 3.01 & 1.8 & $\mathrm{Pt} / \mathrm{Ti} / \mathrm{Au}$ & $\mathrm{Ti} / \mathrm{Al} / \mathrm{Pt} / \mathrm{Au}$ & U. Florida & [5] \\
\hline 2002 & $\mathrm{GaN}$ & 160 & 2.6 & 1.8 & $\mathrm{Pt} / \mathrm{Ti} / \mathrm{Au}$ & $\mathrm{Ti} / \mathrm{Al} / \mathrm{Pt} / \mathrm{Au}$ & U. Florida & [54] \\
\hline 2002 & $\mathrm{GaN}$ & 160 & 3 & 1.8 & $\mathrm{Pt} / \mathrm{Ti} / \mathrm{Au}$ & $\mathrm{Ti} / \mathrm{Al} / \mathrm{Pt} / \mathrm{Au}$ & U. Florida & [53] \\
\hline 2004 & $\mathrm{GaN}$ & 353 & 160 & NA & $\mathrm{Pd} / \mathrm{Mo} / \mathrm{Ti} / \mathrm{Au}$ & $\mathrm{Ti} / \mathrm{Al} / \mathrm{Ni} / \mathrm{Au}$ & Seoul & [73] \\
\hline 2006 & $\mathrm{GaN}$ & 630 & 2.2 & 1.2 & $\mathrm{Pt}$ & $\mathrm{Ti} / \mathrm{Al}$ & U. Auburn & [31] \\
\hline 2007 & GaN & 580 & 1.3 & 1.35 & $\mathrm{Au}$ & $\mathrm{Ti} / \mathrm{Al} / \mathrm{Ti} / \mathrm{Au}$ & Sumitomo & [32] \\
\hline 2009 & $\mathrm{GaN}$ & 680 & 1.1 & 1.2 & $\mathrm{Au}$ & $\mathrm{Ti} / \mathrm{Al} / \mathrm{Ti} / \mathrm{Au}$ & Sumitomo & [68] \\
\hline 2010 & $\mathrm{GaN}$ & 1100 & 0.71 & 1 & $\mathrm{Ni} / \mathrm{Au}$ & $\mathrm{Ti} / \mathrm{Al} / \mathrm{Ti} / \mathrm{Au}$ & Sumitomo & [83] \\
\hline 2010 & GaN & 600 & 1.3 & 0.95 & $\mathrm{Pt}$ & $\mathrm{Ti} / \mathrm{Al} / \mathrm{Ni} / \mathrm{Au}$ & U. Auburn & [29] \\
\hline 2011 & $\mathrm{GaN}$ & 1650 & 9 & 0.5 & $\mathrm{Pt}$ & $\mathrm{Ti} / \mathrm{Al} / \mathrm{Ni} / \mathrm{Au}$ & NCSU & [71] \\
\hline 2011 & Sapphire & 1700 & NA & NA & $\mathrm{Ni}$ & NA & NCSU & [70] \\
\hline 2012 & Sapphire & 230 & 1 & NA & $\mathrm{Ni} / \mathrm{Au}$ & $\mathrm{Ti} / \mathrm{Al} / \mathrm{Ni} / \mathrm{Au}$ & RWTH & [33] \\
\hline 2013 & $\mathrm{GaN}$ & 600 & 1.2 & 0.9 & $\mathrm{Pd}$ & $\mathrm{Al}$ & Avogy & [52] \\
\hline 2014 & $\mathrm{Si}$ & 205 & 6 & 0.5 & $\mathrm{Ni} / \mathrm{Au}$ & $\mathrm{Ti} / \mathrm{Al}$ & MIT & [37] \\
\hline 2014 & $\mathrm{GaN}$ & 620 & 0.89 & 1.46 & $\mathrm{Ni} / \mathrm{Au}$ & NA & Sumitomo & [15] \\
\hline 2015 & $\mathrm{GaN}$ & 790 & $2.25 \sim 2.61$ & 0.5 & $\mathrm{Ni}$ & $\mathrm{Ti} / \mathrm{Al}$ & TOYODA & [67] \\
\hline 2016 & $\mathrm{GaN}$ & 300 & NA & NA & $\mathrm{Ni} / \mathrm{Au}$ & $\mathrm{Ti} / \mathrm{Al} / \mathrm{Ni} / \mathrm{Au}$ & Naval & [65] \\
\hline 2016 & $\mathrm{GaN}$ & 800 & 4.94 & 0.77 & $\mathrm{Ni} / \mathrm{Au}$ & $\mathrm{Ti} / \mathrm{Au}$ & HRL & [17] \\
\hline 2016 & $\mathrm{GaN}$ & 700 & 3.06 & 0.67 & $\mathrm{Ni} / \mathrm{Au}$ & $\mathrm{Ti} / \mathrm{Au}$ & HRL & [19] \\
\hline 2016 & $\mathrm{GaN}$ & 700 & 2 & 0.8 & $\mathrm{Ni} / \mathrm{Au} / \mathrm{Ni}$ & $\mathrm{Ti} / \mathrm{Al}$ & MIT & [75] \\
\hline 2017 & GaN & NA & 0.72 & 0.73 & $\mathrm{Ni} / \mathrm{Au}$ & $\mathrm{Ti} / \mathrm{Al} / \mathrm{Au}$ & MANA & [18] \\
\hline 2017 & GaN & 610 & NA & 0.5 & $\mathrm{Pd} / \mathrm{Au}$ & $\mathrm{Ti} / \mathrm{Al} / \mathrm{Ni} / \mathrm{Au}$ & Naval & [61] \\
\hline 2017 & $\mathrm{GaN}$ & 503 & 1.65 & 0.59 & $\mathrm{Pt} / \mathrm{Au}$ & $\mathrm{Tt} / \mathrm{Al} / \mathrm{Ti} / \mathrm{Au}$ & ASU & [87] \\
\hline 2017 & GaN & 1200 & 7 & 0.69 & TiN & $\mathrm{Ti} / \mathrm{Al}$ & U. Shenzhen & [82] \\
\hline 2017 & $\mathrm{GaN}$ & 600 & 1.7 & 3.5 & $\mathrm{Ni} / \mathrm{Au}$ & $\mathrm{Ti} / \mathrm{Al}$ & MIT & [76] \\
\hline 2017 & $\mathrm{GaN}$ & 600 & 7.6 & 0.7 & $\mathrm{Ni} / \mathrm{Au}$ & $\mathrm{Ti} / \mathrm{Al}$ & MIT & [76] \\
\hline 2017 & Sapphire & 100 & 0.59 & 0.75 & $\mathrm{Ni} / \mathrm{Ti} / \mathrm{Pt} / \mathrm{Au}$ & NA & IIT & [36] \\
\hline 2017 & $\mathrm{Si}$ & 148 & 13.9 & 0.69 & $\mathrm{Ni} / \mathrm{Au}$ & $\mathrm{AuSb} / \mathrm{Au}$ & NIT & [35] \\
\hline 2017 & $\mathrm{GaN}$ & 640 & 1.9 & 1 & $\mathrm{Pd}$ & $\mathrm{Ti} / \mathrm{Au}$ & Cornell & [80] \\
\hline 2018 & $\mathrm{GaN}$ & 995 & 1.3 & 1.7 & $\mathrm{Pt} / \mathrm{Au}$ & $\mathrm{Ti} / \mathrm{Al} / \mathrm{Au}$ & U. Zhejiang & [81] \\
\hline 2018 & $\mathrm{Si}$ & 254 & 1.6 & 0.76 & $\mathrm{Ni} / \mathrm{Au}$ & NA & EPFL & [38] \\
\hline 2019 & $\mathrm{GaN}$ & 802 & 250 & 0.74 & $\mathrm{Ni} / \mathrm{Au}$ & $\mathrm{Ti} / \mathrm{Al} / \mathrm{Ni} / \mathrm{Au}$ & U. Shenzhen & [26] \\
\hline
\end{tabular}

Then, the performance of GaN vertical SBDs with different edge termination techniques are discussed, including field rings, JTE, field plates, trench termination, RESURF, and N-based termination. In the practical design, the breakdown voltage is effectively improved by redistribution of electric field at electrode edges with all these edge termination techniques.

In the future studies, the performance of GaN vertical SBDs should be improved by optimizing the device structure and quality of the epitaxial layers. We hope this review can be valuable for research on GaN vertical power SBDs. 
Author Contributions: All the authors read and approved the final manuscript. Y.S. and X.K. contributed equally to this paper.

Funding: This work was supported in part by the National Key R\&D Program of China (Nos. 2017YFB0403000 and 2016YFB0400100) and the Natural Science Foundation of China (Nos. 61804172 and 61534007).

Acknowledgments: The authors would like to thank the cosupport of the Beijing Delft Institute of Intelligent Science and Technology (BD-IIST) and the Institute of Microelectronics of the Chinese Academy of Sciences (IMECAS). The authors also would like to thank Wei Yue, Weichao Wu, Runze Zhang, Bin Wang, Xueqin Lv, Aixue Zhang, Yang Liu, and Dahai Wang for the technical support.

Conflicts of Interest: The authors declare no conflicts of interest.

\section{References}

1. Flack, T.J.; Pushpakaran, B.N.; Bayne, S.B. GaN technology for power electronic applications: A review. J. Electron. Mater. 2016, 45, 2673-2682.

2. Zhang, Q.G.; Roosmalen, A. More than Moore, 1st ed.; Springer: Berlin/Heidelberg, Germany, $2009 ;$ pp. 85-107.

3. Dang, G.T.; Zhang, A.P.; Mshewa, M.M.; Ren, F.; Chyi, J.I.; Lee, C.M.; Chuo, C.C.; Chi, G.C.; Han, J.; $\mathrm{Chu}$, S.N.G.; et al. High breakdown voltage Au/Pt/GaN Schottky diodes. J. Vac. Sci. Technol. A Vac. Surf. Films 2000, 18, 1135-1138. [CrossRef]

4. Kang, X.; Wang, X.; Huang, S.; Zhang, J.; Liu, X. Recess-free AlGaN/GaN lateral Schottky barrier controlled Schottky rectifier with low turn-on voltage and high reverse blocking. In Proceedings of the 2018 IEEE 30th International Symposium on Power Semiconductor Devices and ICs (ISPSD), Chicago, IL, USA, 13-17 May 2018.

5. Zhang, A.P.; JJohnson, W.; Luo, B.; Ren, F.; Pearton, S.J.; Park, S.S.; Park, Y.J.; Chyi, J.I. Vertical and lateral GaN rectifiers on free-standing GaN substrates. Appl. Phys. Lett. 2001, 79, 1555-1557. [CrossRef]

6. Yang, S.; Han, S.; Li, R.; Sheng, K. $1 \mathrm{kV} / 1.3 \mathrm{~m} \Omega \cdot \mathrm{cm}^{2}$ vertical GaN-on-GaN Schottky barrier diodes with high switching performance. In Proceedings of the 2018 IEEE 30th International Symposium on Power Semiconductor Devices and ICs (ISPSD), Chicago, IL, USA, 13-17 May 2018.

7. Bandić, Z.Z.; Bridger, P.M.; Piquette, E.C.; Mcgill, T.C.; Vaudo, R.P.; Phanse, V.M.; Redwing, J.M. High voltage (450 V) GaN Schottky rectifiers. Appl. Phys. Lett. 1999, 74, 1266-1268. [CrossRef]

8. Saremi, M. Modeling and Simulation of the Programmable Metallization cells (PMCs) and Diamond-Based Power Devices. Ph.D. Thesis, Arizona State University, Tempe, AZ, USA, 2017.

9. Jamali Mahabadi, S.E.; Moghadam, H.A. Comprehensive study of a $4 \mathrm{H}-\mathrm{SiC}$ MES-MOSFET. Phys. E Low-Dimens. Syst. Nanostruct. 2015, 74, 25-29. [CrossRef]

10. Moghadam, H.A.; Dimitrijev, S.; Han, J.; Haasmann, D.; Aminbeidokhti, A. Transient-Current Method for Measurement of Active Near-Interface Oxide Traps in 4H-SiC MOS Capacitors and MOSFETs. IEEE Trans. Electron Devices 2015, 62, 2670-2674. [CrossRef]

11. Saremi, M.; Hathwar, R.; Dutta, M.; Koeck, F.A.M.; Nemanich, R.J.; Chowdhury, S.; Goodnick, S.M. Analysis of the reverse I-V characteristics of diamond-based PIN diodes. Appl. Phys. Lett. 2017, 111, 043507. [CrossRef]

12. Holmes, J.; Dutta, M.; Koeck, F.A.; Benipal, M.; Brown, J.; Fox, B.; Hathwar, R.; Johnson, H.; Malakoutian, M.; Saremi, M.; et al. A $4.5 \mu \mathrm{m}$ PIN diamond diode for detecting slow neutrons. In Nuclear Instruments and Methods in Physics Research Section A: Accelerators, Spectrometers; Detectors and Associated Equipment; Elsevier: Amsterdam, The Netherlands, 2018; Volume 903, pp. 297-301.

13. Chante, J.P.; Locatelli, M.L.; Planson, D.; Ottaviani, L.; Morvan, E.; Isoird, K.; Nallet, F. Silicon carbide power devices. In 1998 International Semiconductor Conference; World Scientific Publishing Company: Singapore, 1998.

14. Baliga, B.J. Gallium nitride devices for power electronic applications. Semicond. Sci. Technol. 2013, $28,074011$. [CrossRef]

15. Ueno, M.; Yoshimoto, S.; Ishihara, K.; Okada, M.; Sumiyoshi, K.; Hirano, H.; Mitsuhashi, F.; Yoshizumi, Y.; Ishizuka, T.; Kiyama, M.; et al. Fast recovery performance of vertical GaN Schottky barrier diodes on low-dislocation-density GaN substrates. In Proceedings of the 2014 IEEE 26th International Symposium on Power Semiconductor Devices \& IC's (ISPSD), Waikoloa, HI, USA, 15-19 June 2014.

16. Tanaka, T.; Kaneda, N.; Mishima, T.; Kihara, Y.; Aoki, T.; Shiojima, K. Roles of lightly doped carbon in the drift layers of vertical n-GaN Schottky diode structures on freestanding GaN substrates. Jpn. J. Appl. Phys. 2015, 54, 041002. [CrossRef] 
17. Cao, Y.; Chu, R.; Li, R.; Chen, M.; Chang, R.; Hughes, B. High-voltage vertical GaN Schottky diode enabled by low-carbon metal-organic chemical vapor deposition growth. Appl. Phys. Lett. 2016, 108, 062103. [CrossRef]

18. Ren, B.; Liao, M.; Sumiya, M.; Wang, L.; Koide, Y.; Sang, L. Nearly ideal vertical GaN Schottky barrier diodes with ultralow turn-on voltage and on-resistance. Appl. Phys. Express 2017, 10, 051001. [CrossRef]

19. Cao, Y.; Chu, R.; Li, R.; Chen, M.; Williams, A.J. Improved performance in vertical GaN Schottky diode assisted by AlGaN tunneling barrier. Appl. Phys. Lett. 2016, 108, 112101. [CrossRef]

20. Hu, J.; Zhang, Y.; Sun, M.; Piedra, D.; Chowdhury, N.; Palacios, T. Materials and processing issues in vertical GaN power electronics. Mater. Sci. Semicond. Process. 2018, 78, 75-84. [CrossRef]

21. Chen, J.; Brewer, W.D. Ohmic Contacts on p-GaN. Adv. Electron. Mater. 2015, 1, 1500113. [CrossRef]

22. Sundaramoorthy, V.; Nistor, I. Design of quasi-vertical GaN high power Schottky diodes based on field plate termination. In CAS 2010 Proceedings (International Semiconductor Conference); IEEE: Piscataway, NJ, USA, 2010.

23. Sumiyoshi, K.; Okada, M.; Ueno, M.; Kiyama, M.; Nakamura, T. Low on-resistance high breakdown voltage GaN diodes on low dislocation density GaN substrates. SEI Tech. Rev. 2013, 77, 113.

24. Motoki, K. Development of gallium nitride substrates. SEI Tech. Rev. 2010, 70, $28-35$.

25. Sang, L.; Ren, B.; Sumiya, M.; Liao, M.; Koide, Y.; Tanaka, A.; Cho, Y.; Harada, Y.; Nabatame, T.; Sekiguchi, T.; et al. Initial leakage current paths in the vertical-type GaN-on-GaN Schottky barrier diodes. Appl. Phys. Lett. 2017, 111, 122102. [CrossRef]

26. Gu, H.; Hu, C.; Wang, J.; Lu, Y.; Ao, J.-P.; Tian, F.; Zhang, Y.; Wang, M.; Liu, X.; Xu, K.; et al. Vertical GaN Schottky barrier diodes on Ge-doped free-standing GaN substrates. J. Alloy. Compd. 2019, 780, 476-481. [CrossRef]

27. Kizilyalli, I.C.; Bui-Quang, P.; Disney, D.; Bhatia, H.; Aktas, O. Reliability studies of vertical GaN devices based on bulk GaN substrates. Microelectron. Reliab. 2015, 55, 1654-1661. [CrossRef]

28. Cao, X.A.; Lu, H.; Leboeuf, S.F.; Cowen, C.; Arthur, S.D.; Wang, W. Growth and characterization of GaN PiN rectifiers on free-standing GaN. Appl. Phys. Lett. 2005, 87, 053503. [CrossRef]

29. Wang, Y.; Alur, S.; Sharma, Y.; Tong, F.; Thapa, R.; Gartland, P.; Issacs-Smith, T.; Ahyi, C.; Williams, J.; Park, M.; et al. Ultra-low leakage and high breakdown Schottky diodes fabricated on free-standing GaN substrate. Semicond. Sci. Technol. 2010, 26, 022002. [CrossRef]

30. Baliga, B.J. Fundamentals of Power Semiconductor Devices; Springer: Berlin/Heidelberg, Germany, 2010.

31. Zhou, Y.; Wang, D.; Ahyi, C.; Tin, C.-C.; Williams, J.; Park, M.; Williams, N.M.; Hanser, A. High breakdown voltage Schottky rectifier fabricated on bulk n-GaN substrate. Solid-State Electron. 2006, 50, 1744-1747. [CrossRef]

32. Hashimoto, S.; Yoshizumi, Y.; Tanabe, T.; Kiyama, M. High-purity GaN epitaxial layers for power devices on low-dislocation-density GaN substrates. J. Cryst. Growth 2007, 298, 871-874. [CrossRef]

33. Witte, W.; Fahle, D.; Koch, H.; Heuken, M.; Kalisch, H.; Vescan, A. Electrical properties of quasi-vertical Schottky diodes. Semicond. Sci. Technol. 2012, 27, 085015. [CrossRef]

34. Johnson, J.W.; Laroch, J.R.; Ren, F.; Gila, B.P.; Overberg, M.E.; Abernathy, C.R.; Chyi, J.I.; Chuo, C.C.; Nee, T.E.; Lee, C.M.; et al. Schottky rectifiers fabricated on free-standing GaN substrates. Solid-State Electron. 2001, 45, 405-410. [CrossRef]

35. Zhang, K.; Mase, S.; Nakamura, K.; Hamada, T.; Egawa, T. Demonstration of fully vertical GaN-on-Si Schottky diode. Electron. Lett. 2017, 53, 1610-1611. [CrossRef]

36. Sabui, G.; Zubialevich, V.Z.; White, M.; Pampili, P.; Parbrook, P.J.; Mclaren, M.; Arredondo-Arechavala, M.; Shen, Z.J. GaN Nanowire Schottky Barrier Diodes. IEEE Trans. Electron Devices 2017, 64, 2283-2290. [CrossRef]

37. Zhang, Y.; Sun, M.; Piedra, D.; Azize, M.; Zhang, X.; Fujishima, T.; Palacios, T. GaN-on-Si vertical Schottky and p-n diodes. IEEE Electron Device Lett. 2014, 35, 618-620.

38. Liu, C.; Khadar, R.A.; Matioli, E. Vertical GaN-on-Si MOSFETs with monolithically integrated freewheeling Schottky Barrier Diodes. IEEE Electron Device Lett. 2018, 39, 1034-1037. [CrossRef]

39. Zhang, Y.; Dadgar, A.; Palacios, T. Gallium nitride vertical power devices on foreign substrates: A review and outlook. J. Phys. D Appl. Phys. 2018, 51, 273001. [CrossRef]

40. Pengelly, R.S.; Wood, S.M.; Milligan, J.W.; Sheppard, S.T.; Pribble, W.L. A review of GaN on SiC high electron-mobility power transistors and MMICs. IEEE Trans. Microw. Theory Tech. 2012, 60, 1764-1783. [CrossRef] 
41. Ma, J.; Zanuz, D.C.; Matioli, E. Field plate design for low leakage current in lateral GaN power Schottky diodes: Role of the pinch-off voltage. IEEE Electron Device Lett. 2017, 38, 1298-1301. [CrossRef]

42. Baliga, B.J. Power semiconductor device figure of merit for high-frequency applications. IEEE Electron Device Lett. 1989, 10, 455-457. [CrossRef]

43. Yu, H.; Duan, T. Gallium Nitride Power Devices, 1st ed.; Springer: Berlin/Heidelberg, Germany, 2017; pp. 193-239.

44. Crowell, C.R.; Sze, S.M. Current transport in metal-semiconductor barriers. Solid-State Electron. 1966, 9 , 1035-1048. [CrossRef]

45. Khemka, V.; Patel, R.; Chow, T.P.; Gutmann, R.J. Design considerations and experimental analysis for silicon carbide power rectifiers. Solid-State Electron. 1999, 43, 1945-1962. [CrossRef]

46. Baliga, J. Modern Power Devices; John Wiley and Sons Inc.: New York, NY, USA, 1987.

47. Chow, T.P.; Ramungul, N.; Fedison, J.; Tang, Y. SiC Power Bipolar Transistors and Thyristors, in Silicon Carbide: Recent Major Advances; Choyke, W.J., Matsunami, H., Pensl, G., Eds.; Springer: Berlin/Heidelberg, Germany, 2004; pp. 737-767.

48. Tsao, J.Y.; Chowdhury, S.; Hollis, M.A.; Jena, D.; Johnson, N.M.; Jones, K.A.; Kaplar, R.J.; Rajan, S.; van de Walle, C.G.; Bellotti, E.; et al. Ultrawide-bandgap semiconductors: Research opportunities and challenges. Adv. Electron. Mater. 2018, 4, 1600501. [CrossRef]

49. Hasegawa, H.; Oyama, S. Mechanism of anomalous current transport in n-type GaN Schottky contacts. J. Vac. Sci. Technol. B: Microelectron. Nanometer Struct. Process. Meas. Phenom. 2002, 20, 1647-1655. [CrossRef]

50. Miller, E.J.; Yu, E.T.; Waltereit, P.; Speck, J.S. Analysis of reverse-bias leakage current mechanisms in GaN grown by molecular-beam epitaxy. Appl. Phys. Lett. 2004, 84, 535-537. [CrossRef]

51. Zhang, H.; Miller, E.J.; Yu, E.T. Analysis of leakage current mechanisms in Schottky contacts to GaN and Al0.25Ga0.75N/GaN grown by molecular-beam epitaxy. J. Appl. Phys. 2006, 99, 023703. [CrossRef]

52. Disney, D.; Nie, H.; Edwards, A.; Bour, D.; Shah, H.; Kizilyalli, I.C. Vertical power diodes in bulk GaN. In Proceedings of the 2013 25th International Symposium on Power Semiconductor Devices \& IC's (ISPSD), Kanazawa, Japan, 26-30 May 2013.

53. Johnson, J.W.; Zhang, A.P.; Wen-Ben, L.; Fan, R.; Pearton, S.J.; Park, S.S.; Park, Y.J.; Jenn-Inn, C. Breakdown voltage and reverse recovery characteristics of free-standing GaN Schottky rectifiers. IEEE Trans. Electron Devices 2002, 49, 32-36. [CrossRef]

54. Ip, K.; Baik, K.H.; Luo, B.; Ren, F.; Pearton, S.J.; Park, S.S.; Park, Y.J.; Zhang, A.P. High current bulk GaN Schottky rectifiers. Solid-State Electron. 2002, 46, 2169-2172. [CrossRef]

55. Laroche, J.R.; Ren, F.; Baik, K.W.; Pearton, S.J.; Shelton, B.S.; Peres, B. Design of edge termination for GaN power Schottky diodes. J. Electron. Mater. 2005, 34, 370-374. [CrossRef]

56. Qi, C.; Wang, Q.; Wang, L.; Liu, Z.; Yi, X.; Li, J.; Wang, J. A novel surface treatment for the sliver ohmic contacts to P-GaN. In Proceedings of the 2016 13th China International Forum on Solid State Lighting (SSLChina), Beijing, China, 15-17 November 2016.

57. Oh, M.; Kim, H. Highly Reflective Nonalloyed Ni/Ag/Pt Contact to Mg-Si Codoped p-GaN for Enhanced Efficiency of Light-Emitting Diodes. J. Nanosci. Nanotechnol. 2015, 15, 7531-7536. [CrossRef]

58. Wenzel, R.; Fischer, G.G.; Schmid-Fetzer, R. Ohmic contacts on p-GaN (Part II): Impact of semiconductor fabrication and surface treatment. Mater. Sci. Semicond. Process. 2001, 4, 367-371. [CrossRef]

59. Feigelson, B.N.; Anderson, T.J.; Abraham, M.; Freitas, J.A.; Hite, J.K.; Eddy, C.R.; Kub, F.J. Multicycle rapid thermal annealing technique and its application for the electrical activation of $\mathrm{Mg}$ implanted in $\mathrm{GaN}$. J. Cryst. Growth 2012, 350, 21-26. [CrossRef]

60. Greenlee, J.D.; Anderson, T.J.; Feigelson, B.N.; Wheeler, V.D.; Hobart, K.D.; Kub, F.J. Comparison of AlN encapsulants for bulk GaN Multicycle rapid thermal annealing. ECS J. Solid State Sci. Technol. 2015, 4, 403-407. [CrossRef]

61. Koehler, A.D.; Anderson, T.J.; Tadjer, M.J.; Nath, A.; Feigelson, B.N.; Shahin, D.I.; Hobart, K.D.; Kub, F.J. Vertical GaN junction barrier Schottky diodes. ECS J. Solid State Sci. Technol. 2016, 6, 10-12. [CrossRef]

62. Anderson, T.J.; Feigelson, B.N.; Kub, F.J.; Tadjer, M.J.; Hobart, K.D.; Mastro, M.A.; Hite, J.K.; Eddy, C.R., Jr. Activation of Mg implanted in GaN by multicycle rapid thermal annealing. Electron. Lett. 2014, 50, 197-198. [CrossRef] 
63. Greenlee, J.D.; Feigelson, B.N.; Anderson, T.J.; Hite, J.K.; Hobart, K.D.; Kub, F.J. Symmetric multicycle rapid thermal annealing: Enhanced activation of implanted dopants in GaN. ECS J. Solid State Sci. Technol. 2015, 4, 382-386. [CrossRef]

64. Temple, V.A.K. Junction termination extension (JTE), A new technique for increasing avalanche breakdown voltage and controlling surface electric fields in P-N junctions. In Proceedings of the 1977 International Electron Devices Meeting, Washington, DC, USA, 5-7 December 1977.

65. Anderson, T.J.; Greenlee, J.D.; Feigelson, B.N.; Hite, J.K.; Kub, F.J.; Hobart, K.D. Improved vertical GaN Schottky diodes with ion implanted junction termination extension. ECS J. Solid State Sci. Technol. 2016, 5, 176-178. [CrossRef]

66. Baliga, B.J. Advanced Power Rectifier Concepts; Springer: Berlin/Heidelberg, Germany, 2009.

67. Tanaka, N.; Hasegawa, K.; Yasunishi, K.; Murakami, N.; Oka, T. 50 A vertical GaN Schottky barrier diode on a free-standing GaN substrate with blocking voltage of 790 V. Appl. Phys. Express 2015, 8, 071001. [CrossRef]

68. Horii, T.; Miyazaki, T.; Saito, Y.; Hashimoto, S.; Tanabe, T.; Kiyama, M. High-breakdown-voltage GaN vertical Schottky barrier diodes with field plate structure. Mater. Sci. Forum 2009, 15, 963-966. [CrossRef]

69. Zhang, Y.; Sun, M.; Wong, H.; Lin, Y.; Srivastava, P.; Hatem, C.; Azize, M.; Piedra, D.; Yu, L.; Sumitomo, T.; et al. Origin and control of off-state leakage current in GaN-on-Si vertical diodes. IEEE Trans. Electron. Devices 2015, 62, 2155-2161. [CrossRef]

70. Ozbek, A.M.; Baliga, B.J. Finite-Zone Argon implant edge termination for high-voltage GaN Schottky rectifiers. IEEE Electron Device Lett. 2011, 32, 1361-1363. [CrossRef]

71. Ozbek, A.M.; Baliga, B.J. Planar nearly ideal edge-termination technique for GaN devices. IEEE Electron Device Lett. 2011, 32, 300-302. [CrossRef]

72. Grove, A.S.; Leistiko, O.; Hooper, W.W. Effect of surface fields on the breakdown voltage of planar silicon p-n junctions. IEEE Trans. Electron Devices 1967, 14, 157-162. [CrossRef]

73. Seung-Chul, L.; Jin-Cherl, H.; Soo-Seong, K.; Min-Woo, H.; Kwang-Seok, S.; Yearn-Ik, C.; Min-Koo, H. A new vertical GaN Schottky barrier diode with floating metal ring for high breakdown voltage. In Proceedings of the 2004 Proceedings of the 16th International Symposium on Power Semiconductor Devices and ICs, Kitakyushu, Japan, 24-27 May 2004.

74. Bhatnagar, M.; Nakanishi, H.; Bothra, S.; Mclarty, P.K.; Baliga, B.J. Edge terminations for SiC high voltage Schottky rectifiers. In Proceedings of the 5th International Symposium on Power Semiconductor Devices and ICs, Monterey, CA, USA, 18-20 May 1993.

75. Zhang, Y.; Sun, M.; Liu, Z.; Piedra, D.; Pan, M.; Gao, X.; Lin, Y.; Zubair, A.; Yu, L.; Palacios, T.; et al. Novel GaN trench MIS barrier Schottky rectifiers with implanted field rings. In Proceedings of the 2016 IEEE International Electron Devices Meeting (IEDM), San Francisco, CA, USA, 3-7 December 2016.

76. Zhang, Y.; Liu, Z.; Tadjer, M.J.; Sun, M.; Piedra, D.; Hatem, C.; Anderson, T.J.; Luna, L.E.; Nath, A.; Palacios, T.; et al. Vertical GaN junction barrier Schottky rectifiers by selective ion implantation. IEEE Electron Device Lett. 2017, 38, 1097-1100. [CrossRef]

77. Qiao, M.; Hu, X.; Wen, H.; Wang, M.; Luo, B.; Luo, X.; Wang, Z.; Zhang, B.; Li, Z. A novel substrate-assisted RESURF technology for small curvature radius junction. In Proceedings of the 2011 IEEE 23rd International Symposium on Power Semiconductor Devices and ICs, San Diego, CA, USA, 23-26 May 2011.

78. Ludikhuize, A.W. A review of RESURF technology. In Proceedings of the 12th International Symposium on Power Semiconductor Devices and ICs, Toulouse, France, 22-25 May 2000.

79. Qiao, M.; Wang, Y.; Zhou, X.; Jin, F.; Wang, H.; Wang, Z.; Li, Z.; Zhang, B. Analytical modeling for a novel triple RESURF LDMOS with N-Top layer. IEEE Trans. Electron Devices 2015, 62, 2933-2939. [CrossRef]

80. Li, W.; Nomoto, K.; Pilla, M.; Pan, M.; Gao, X.; Jena, D.; Xing, H.G. Design and realization of GaN trench junction-barrier-Schottky-diodes. IEEE Trans. Electron Devices 2017, 64, 1635-1641. [CrossRef]

81. Han, S.; Yang, S.; Sheng, K. High-voltage and high- $\mathrm{I}_{\mathrm{on}} / \mathrm{I}_{\text {off }}$ vertical GaN-on-GaN Schottky barrier diode with nitridation-based termination. IEEE Electron Device Lett. 2018, 39, 572-575. [CrossRef]

82. Liu, X.; Liu, Q.; Li, C.; Wang, J.; Yu, W.; Xu, K.; Ao, J.-P. 1.2 kV GaN Schottky barrier diodes on free-standing GaN wafer using a CMOS-compatible contact material. Jpn. J. Appl. Phys. 2017, 56, 026501. [CrossRef]

83. Saitoh, Y.; Sumiyoshi, K.; Okada, M.; Horii, T.; Miyazaki, T.; Shiomi, H.; Ueno, M.; Katayama, K.; Kiyama, M.; Nakamura, T.; et al. Extremely low on-resistance and high breakdown voltage observed in vertical GaN Schottky barrier diodes with high-mobility drift layers on low-dislocation-density gan substrates. Appl. Phys. Express 2010, 3, 081001. [CrossRef] 
84. Shui-Jinn, W.; Shu-Cheng, C.; Uang, K.; Bor-Wen, L. Vertical-structured Ni/n-GaN schottky diode with electroplating nickel substrate. In Proceedings of the 63rd Device Research Conference Digest, Santa Barbara, CA, USA, 20-22 June 2005.

85. Mastro, M.; Kryliouk, O.; Reed, M.; Anderson, T.; Davydov, A.; Shapiro, A. Thermal stability of MOCVD and HVPE GaN layers in $\mathrm{H}_{2}, \mathrm{HCl}, \mathrm{NH}_{3}$ and $\mathrm{N}_{2}$. Phys. Status Solidi A 2001, 188, 467-471. [CrossRef]

86. Zhu, T.G.; Lambert, D.J.H.; Shelton, B.S.; Wong, M.M.; Chowdhury, U.; Dupuis, R.D. High-voltage mesa-structure GaN Schottky rectifiers processed by dry and wet etching. Appl. Phys. Lett. 2000, 77, 2918-2920. [CrossRef]

87. Fu, H.; Huang, X.; Chen, H.; Lu, Z.; Baranowski, I.; Zhao, Y. Ultra-low turn-on voltage and on-resistance vertical GaN-on-GaN Schottky power diodes with high mobility double drift layers. Appl. Phys. Lett. 2017, 111, 152102. [CrossRef]

88. Zhang, A.P.; Dang, G.; Ren, F.; Han, J.; Cho, H.; Pearton, S.J.; Chyi, J.I.; Nee, T.E.; Lee, C.M.; Chu, S.N.G.; et al. Forward turn-on and reverse blocking characteristics of GaN Schottky and p-i-n rectifiers. Solid-State Electron. 2000, 44, 1157-1161. [CrossRef]

(C) 2019 by the authors. Licensee MDPI, Basel, Switzerland. This article is an open access article distributed under the terms and conditions of the Creative Commons Attribution (CC BY) license (http://creativecommons.org/licenses/by/4.0/). 